\title{
DESCRIPTION BOTANICAL PARK IN THE WORLD
}

\author{
Katerina Despot, Vaska Sandeva, Sanja Stevcheva \\ Goce Delcev University of Stip, R. Macedonia \\ Krste Misirkov b.b. P.O. Box 201 Stip 2000, Macedonia, \\ e-mail: katerina.despot@ugd.edu.mk, vaska.sandeva@ugd.edu.mk
}

\begin{abstract}
A green wall is a wall partially or completely covered with greenery that includes a growing medium, such as soil. Most green walls also feature an integrated water delivery system. Green walls are also known as living walls or vertical gardens. Green walls are used as one of means which for many years have been used to enrich the appearance of building elevations. They make it possible to introduce greenery into urban areas, which are often limited by the size of the building plot. They add an exceptional aesthetic aspect to the so-called 'blind' walls found in city centers. Green walls not only bring with them an element of beauty and integration with nature, but by being used to a wider extent, could also have a positive impact on the city's microclimate. Various technologies enable the creation of green walls on the outside of buildings as well as in semi-open spaces and interiors. In this publication, five different methods of setting up living walls are described, from the relatively simple technique of planting climbers that easily cover bare walls to modular panel systems or green wall systems with flower pots to 'living wall' solutions and finally, to Patrick Blanc's highly sophisticated vertical garden technology.
\end{abstract}

Keywords: vertical garden, green wall, technology and construction.

\section{INTRODUCTION}

In today's world, many businesses and institutions are making sustainability their main priority. This is because of the adverse effects of environmental degradation, resource depletion, and climate change on our society. Our society is providing new environmentally friendly technologies to reduce carbon emissions, improve air quality, and provide health benefits. Even with the resources and technologies available, many businesses make sustainable efforts only if the project is economically feasible, with a proper payback period. Hence, a proper analysis of the feasibility of a sustainable project is done with the help of life-cycle assessment (LCA). As opposed to an economical study, a LCA addresses potential environmental impacts, availability of resources, construction costs and limitations, and other aspects of a sustainable project. A LCA of green walls analyzes the mentioned criteria to determine whether it is a feasible solution in aiding the environment.

\section{BACKGROUND - TYPES OF GREEN WALLS}

Green walls, also known as living walls or vertical gardens, are man-made stable ecosystems attached to the walls of buildings. As seen in Figures 1 and 2, a green wall can be located on either the interior or exterior of a building. Exterior green walls generally reduce energy consumption and help with the urban heat island effect, while interior green walls are used for a healthier and stress free environment. 


\section{IRTTL} Ipplied Resseirlches in Teechnics, Technologies and Eductition Journal of the Faculty of Technics and Technologies, Trakia University https://sites.google.com/a/trakia-uni.bg/artte/

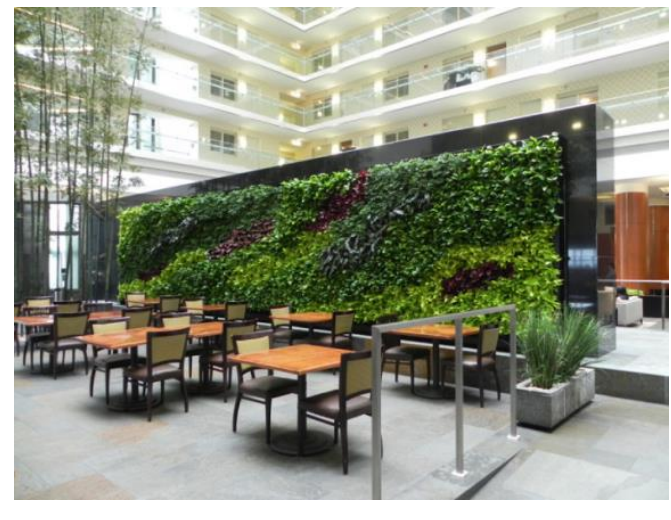

Figure 1. Interior wall

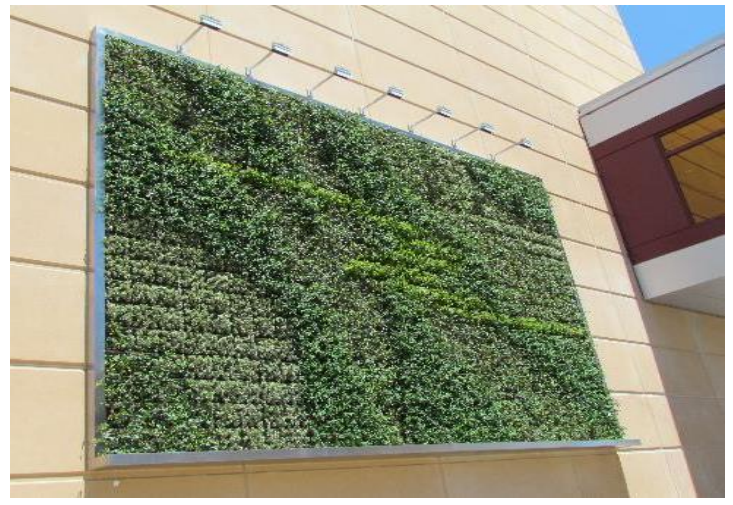

Figure 2. Exterior wall

According to the company, Green Roof Technologies (2014), there are four general kinds of green walls - Extensive, Free Standing, Semi-intensive and Intensive. Figure 3 shows the different characteristics and appearance of these green walls. Extensive walls are the most commonly found walls, comprising of vines growing on the sides of buildings. They have little to no maintenance as well as a very low installation cost. Freestanding walls do not need a building's support to grow, like trimmed bushes in a garden. Semi-Intensive walls are made with a wire mesh to support the vines and creepers for growth ("Green Walls," 2014). However, Intensive Walls have a more intricate framework for plants to grow on. For example, an Intensive panel system wall has the plants' roots embedded in soil panels that are pre-cultivated off site. Intensive walls tend to be around 7-15 cm deep, which allows for the growth of larger plants ("Green Walls," 2014). An intensive green wall is the costliest green wall, but provides the most environmental benefits due to its size and design.

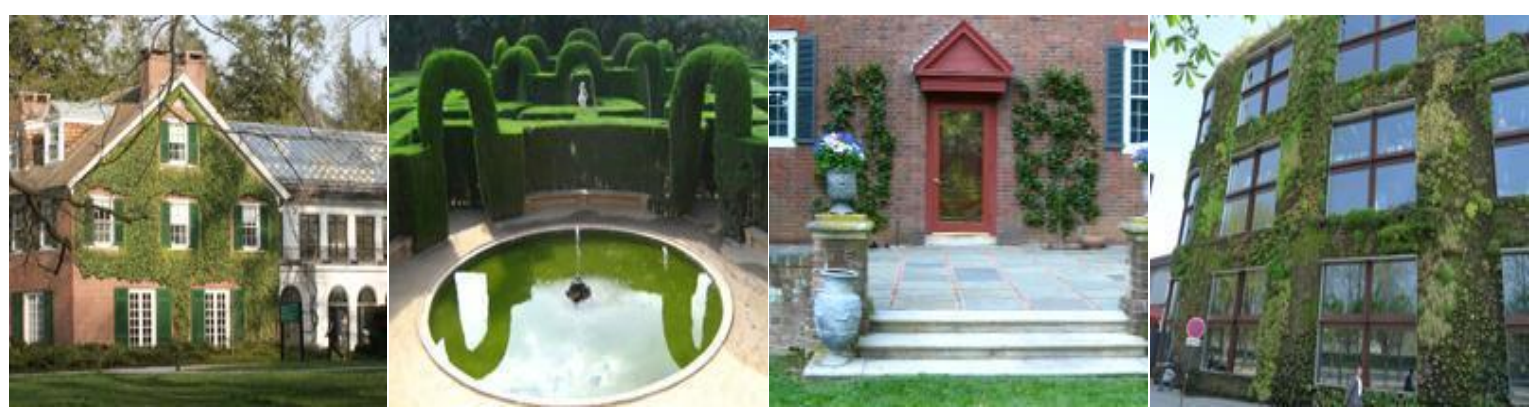

Figure 3.

From left to right- An extensive, freestanding, semi intensive, and intensive green wall

Green walls are recently becoming more and more popular across the globe. They are widespread in Europe and other areas of warmer temperatures, although with the proper plant variety, they can be made to survive in the colder climates. A well-known exterior green wall is the II Fiordaliso Shopping Center in Milan, Italy (Figure 4), which is 4144 meters wide and covered with over 44,000 plants (Zimmer, 2012). Green walls are also popular in Singapore and Germany, where many buildings are being designed to integrate green walls panels into their structure. 


\section{ARTITE $Y$}

Ipplied Reseirlorhes in Technicis, Technologies ind Bductition

Journal of the Faculty of Technics and Technologies, Trakia University https://sites.google.com/a/trakia-uni.bg/artte/

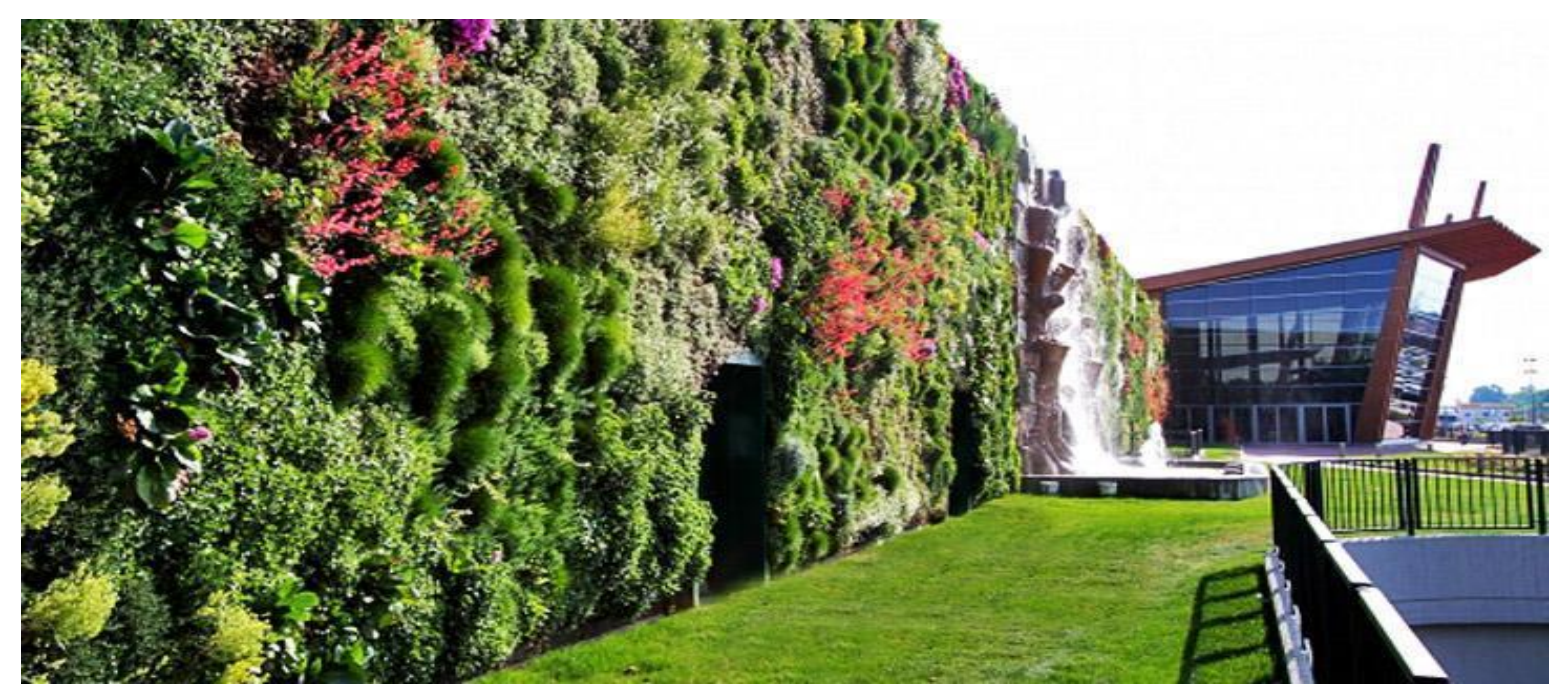

Figure 4. The II Fiordaliso Shopping Center

\section{PATRICK BLANC'S TECHNOLOGY}

On the basis of many years of studies and numerous travels to tropical rainforests, Patrick Blanc described the most-simple solution in his patent entitled 'Design for growing plants without soil on a vertical surface'. In this document, he presented a structure consisting of a vertical surface covered with felt, which is a substitute for soil and retains water. The whole structure consists of a framework from a vertical PVC sheet additionally covered in polypropylene foil. Two layers of felt are attached with the aid of fasteners. The plants require access to light, carbon dioxide and mineral-enriched water. The construction possesses an automatic plant water moisturizing system regulated by a moisture meter.

The roots develop not in a capacitive but on a flat surface, unlike many other soilless cultivation systems where the roots grow inside a capacity filled with certain substances (for example peat, mineral cotton, coconut fiber, or polystyrene mixtures). The weight of the whole vertical installation is very significant. Thinner materials like felt are not deformed by changes of temperature. Micro-fissures between fibers can expand in freezing conditions without changes to its general structure. This is because fibers are nonstructural woven materials. The durability of the material is strengthened with polypropylene foil placed between the fabric and PVC sheets.

Felt does not decompose because it is made of acrylic fibers. Of all the elements of the vertical garden, only felt has an influence on the plants' biology. In its fibers, the roots can grow and become rooted, and absorb water and nutrients. In reality, this fabric can be compared to a thin layer of algae and moss growing on rocks and tree trunks. Different species of plants in the vertical garden grow into the fabric just like they would grow into beds of moss on a rocky surface. In order to facilitate plant installation, the fabric consists of two layers fixed (with stainless steel fasteners) to a durable PVC construction with a layer of polyurethane foil. In the first layer, vertical openings $5 \mathrm{~cm}$ to $10 \mathrm{~cm}$ wide are cut, depending on the dimensions of the plants. Soil is removed from the plants and their roots are placed between both layers.

Initially, fibers and steel fasteners hold the plant. Later the roots start to grow in all directions. The roots grow into the fabric and entwine around the fasteners. Thanks to this process, the plant is able to hold itself. Some of the shrubs' roots can be as much as several meter long. The completely open structure is only limited by its dimensions. This enables the shrubs and

IRITIE Vol. 4, No. 2, 2016 ISSN 1314-8788 (print), ISSN 1314-8796 (online), doi: 10.15547/artte.2016.02.009 


\section{ARTTIE $Y$}

Ipplied Reseirlches in Teechnics, Technologies and Eductition

Journal of the Faculty of Technics and Technologies, Trakia University https://sites.google.com/a/trakia-uni.bg/artte/

small plants to coexist, because the fabric is able to evenly distribute water and nutrients in its entire surface. The entire exchange between plant roots, water and air occurs in the irrigation fabric. In the fabric, an interaction occurs between microorganisms and plants, this enables the roots to absorb more water and mineral salts.

Microorganisms interacting with the roots can convert toxins (such as pesticides, different organic mixtures and volatile organic compounds) emitted by industry, vehicles and the biological activity of humans and animals into less harmful substances. City dust is an additional impurity. Electrostatic forces keep this dust on the surface of leaves. In vertical gardens, dust washed out by rain, gathers in the felt. There, it is decomposed by microorganisms into substances which the plant can absorb. This irrigation fabric becomes a certain type of ecosystem in which different biological processes occur. It is irrigated by a plastic tube made of low density polyurethane which makes it more resistant to deformations caused by water freezing. This tube is arranged horizontally and has 2 millimeter openings placed every $10 \mathrm{~cm}$. Water is supplied to the plants at an appropriate pressure, 3-5 times a day, depending on the time of year. Each irrigation lasts from 1 to 3 minutes. To maintain mineral balance in the root systems, a fertilizer is applied which is much more diluted than that used in farming or gardening. If rain-water is used for irrigation, the density is even lower due to the fact that such water contains calcium carbonate which partly prevents the absorption of useful ions. Depending on exposure to the wind and sun, time of year and if water retention is used, a vertical garden requires a daily amount of 0.5 to 5 liters of water per meter squared.

A vertical garden must have its own construction. This structure consists of a stiff, waterresistant, non-toxic material. Blanc initially used wooden panels, attempting to recreate tree trunks that exist in the natural environment. With regular irrigation, they lasted 3-5 years. He then started to use PVC, which turned out to be ideal. With $10 \mathrm{~mm}$ long fasteners, the wooden panels are able to withstand a weight of $100 \mathrm{~kg} / \mathrm{cm} 2$. A stiff PVC panel can be directly attached to a wall supporting a vertical garden. Circulation of air between the wall and the PVC panel is, however, recommended. One of the various solutions to this is a framed construction made of metal pipes (aluminum, galvanized or stainless steel) which is attached to the wall. This construction has a rectangular grid built from pipes with square cross-sections, each $4 \mathrm{~cm}$ long.

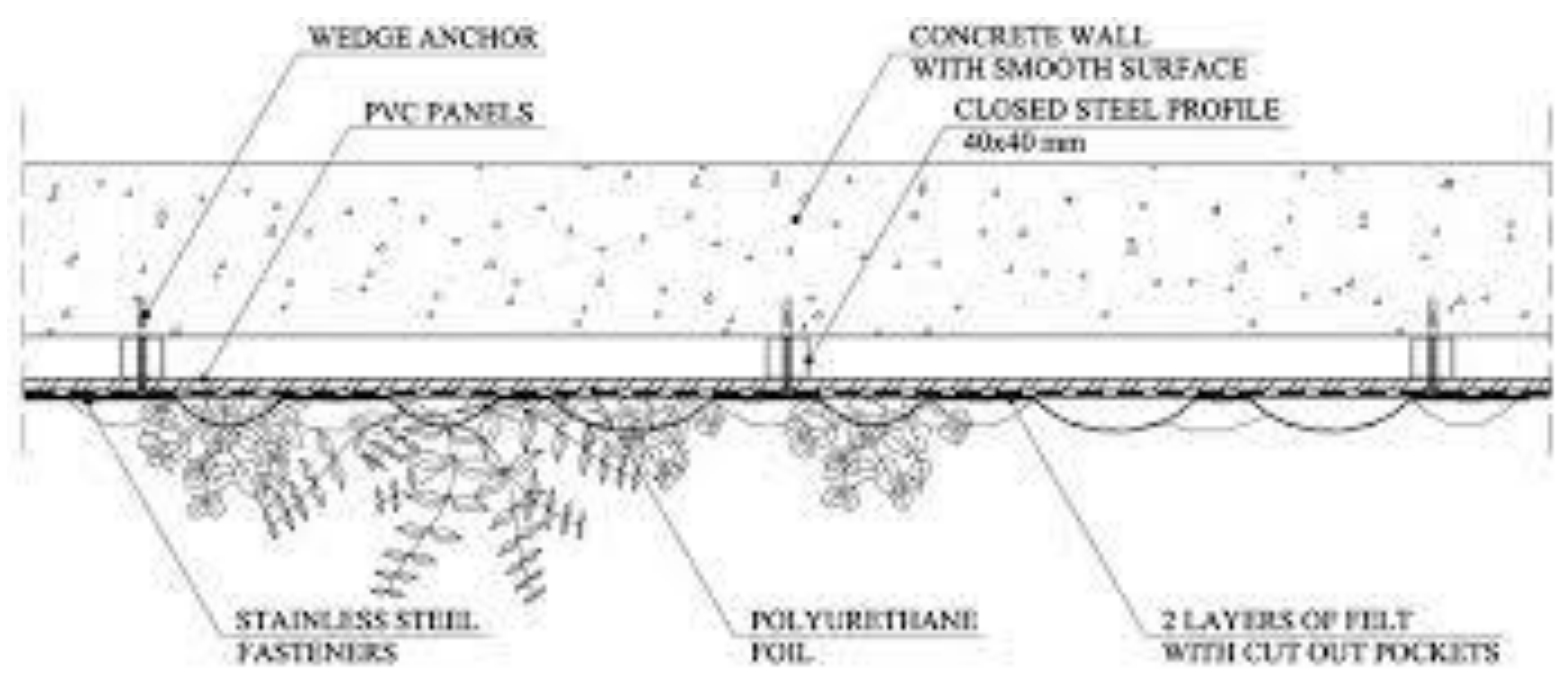

Figure 5. Patrick Blanc's green wall solution 


\section{ART'TE

The connected pipes form a grid of dimensions $60 \times 60 \mathrm{~cm}$. Sometimes, constructors prefer to install vertical pipes with horizontal bars attached to where the PVC panels abut. The panels are riveted to the metal pipes. Silicon is used to seal pipe connections and protect them from water. The weight of the vertical garden is quite low. 10 millimeter PVC panels weigh $7 \mathrm{~kg}$ per $\mathrm{m} 2$. One must add $3-5 \mathrm{~kg} / \mathrm{m} 2$ for irrigating fabric, depending on how much water it contains, and 1 to $5 \mathrm{~kg} / \mathrm{m} 2$ for the plants (depending on the species). This gives an average of $15 \mathrm{~kg} / \mathrm{m} 2$ for a structure enabling the growth and long-term stability of the plants. The whole construction together with the metal frame may weigh from 20 to $50 \mathrm{~kg} / \mathrm{m} 2$. Patrick Blanc's green wall solution is shown in the detail (figure 5). Plants together with irrigating material, a $1 \mathrm{~cm}$ panel and a $4 \mathrm{~cm}$ gap created by the metal frame, constitute a solid insulation from the cold in winter and the heat in summer. The vertical garden may serve as part of a renovated old and abandoned building, giving insulation, visual comfort and better air quality.

Patrick Blanc uses several criteria in order to plan the sequence, arrangement and selection of plant species used for each project. The most important criteria being geographical location, latitude, and the direction of light towards which the garden is exposed8. In turn, as far as internal gardens are concerned, the same climate can be ensured in every location. A comfortable temperature for humans is around 20 degrees Celsius. This is comparable with the temperature of forest undergrowth (a layer in the ecosystem consisting of bushes) in tropical forests at a height of $600 \mathrm{~cm}$ to $800 \mathrm{~cm}$. The case is similar with the amount of available light possibly achieved in closed spaces $(1,500$ to $2,000 \mathrm{~lx}$, which is $1.5 \%$ to $2 \%$ of full sunlight). Relative humidity amounts to around $50 \%$, whereas in the tropical forest undergrowth, it ranges between $85 \%$ and $95 \%$. Low humidity is unfavorable for plants since it exposes the plant to dryness. A vertical garden has its own micro-climate in relation to the surrounding level of humidity. The fact that the irrigating fabric is constantly moist, and that plants release water back outside, improves the conditions of growth for the whole garden and enables more delicate plants to be cultivated which would not survive in ordinary flowerpots.

All the selected species in each project are arranged in a particular sequence. This is selected depending on the climatic conditions occurring in different parts of the vertical garden, and also on the rate of growth and the aesthetic and structural aspects of each species. As far as external gardens are concerned, Blanc attempts to recreate the plant strata occurring on cliffs. This means that plants are fully exposed to wind and sun at the top, and at the bottom, the rock base which is partly embedded in undergrowth (a layer of bushes) and protected from wind and big changes in humidity and temperature. In internal gardens, Patrick Blanc prefers to plan the strata which occurs in forest canopies. An appropriate combination of species in a vertical garden is an important factor contributing to the general impression of the whole garden. The combination must result from an understanding of how the plants evolved. A garden must look to be thriving already several weeks after installation and should grow and create the same impression for many years. The plants planted next to each other should grow at a similar rate in order to avoid competition for space and subsequent overcrowding. Plants in high gardens must be able to withstand strong winds, large fluctuations in temperature and the drying out of irrigation material between watering. To achieve a harmonious plant combination, one must take into consideration the spatial characteristics of each plant, the way it branches out, where and how its roots naturally grow, leaf density, dimension, size, texture and color of leaves, and how they absorb and reflect light. Plants are arranged on the basis of their ecological, structural and chromatic characteristics, giving each vertical garden a unique identity which changes over time.

Vertical gardens must be nurtured because they are a collection of living organisms. An efficient system of irrigation should be constantly ensured for at least several days,

IRTIII Vol. 4, No. 2, 2016 ISSN 1314-8788 (print), ISSN 1314-8796 (online), doi: 10.15547/artte.2016.02.009 


\section{ARTTIE Y}

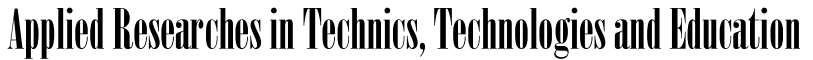

Journal of the Faculty of Technics and Technologies, Trakia University https://sites.google.com/a/trakia-uni.bg/artte/

especially in summer. If need arises, additional light should be given. Technical maintenance of the garden involves several annual inspections, usually once every three months for external gardens and two for internal ones. Some species require little special care. Species with well-developed shoots, such as shrubs, need to be trimmed with garden shears to prevent them from branching out too much. The branches of shrubs should be no longer than 2 meters to minimize the movement of the plants' center of gravity in relation to their supporting vertical garden.

\section{BENEFITS}

Along with being aesthetically appealing, green walls can provide many environmental and financial benefits. There can be a reduction in cooling costs inside a building due to the additional layer of protection that limits UV radiation in the summer. A reduction of heating costs can occur in the winter as the green wall acts as insulation and prevents heat transfer through the walls. This not only reduces the total energy costs in heating and cooling, but also helps counteract the urban heat island effect. An urban heat island is a phenomenon observed in densely populated regions surrounded by rural area, in which the urban area has higher temperature fluctuations than the surrounding area. This is because of the larger population producing higher carbon emissions and the buildings trapping in solar radiation.

Plants are one of the fastest, most cost effective agents for rectifying negative perceptions of an area, enhancing a buildings public profile and significantly improving the visual amenity, economic, and social conditions of the city. The application of vertical gardens is shown to increase property values by dramatically increasing the amenity of buildings, and establishing higher public acclaim, transforming them into recognizable landmarks.

Building protection is primarily produced by reducing temperature fluctuations of the building envelope. Decreased temperature fluctuations reduce the expansion and contraction of building materials and extend the building's lifespan. Green Walls shield the building envelope from ultra-violet rays and acidic rain by reducing cracking and carbonization of the building envelope, the buildings durability is improved and its service life extended.

Soil and plants which used for plant arrangements in Vertical Gardens, have a voice absorption feature. For this reason they perform to decrease voice function which happened both in building and its close area Green Walls provide a noise buffer which significantly reduces outside noise and vibration (up to $40 \mathrm{~dB}$ ) inside our homes and workplaces. A small indoor hedge placed around a workspace will reduce noise by 5 decibels.

One of the biggest benefits of vertical gardens is how they manage water. For starters, watering is very efficient as it is done using a drip irrigation system or a hydroponic system. Any waste water is collected at the bottom of the garden in a special tray where it is drained away. Alternatively, it can be recycled and put back on the garden. This means that practically all the water is used up by the plants and there is very little waste. There is also no runoff into storm water systems so natural waterways are not affected by pollutants that can be found in storm water or waste water.

A green wall offers immediate environmental advances in reducing existing greenhouse and other volatile organic compounds from our polluted cities. Plants act as bio-purifiers and can play a dramatic role in improving the quality of city air through a number of biochemical processes by removing and breaking down airborne contaminants from both inside and outside a building. When combined with plant photosynthesis, which produces clean, oxygen rich air, it becomes easy to see the value of employing living plants as bio-purifiers in polluted urban environments. Approximately 1 square foot of vegetated wall area will filter the air for approximately 100 square feet of office area. Considered in very general sense, planting one wall of any house which situated 50 houses on the street is equal to plant 50 trees on this street. Yet another benefit of vertical gardens is that they improve the air quality

IRTIIE Vol. 4, No. 2, 2016 ISSN 1314-8788 (print), ISSN 1314-8796 (online), doi: 10.15547/artte.2016.02.009 


\section{ARTTIE Y}

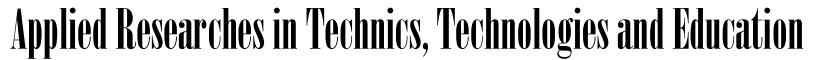

Journal of the Faculty of Technics and Technologies, Trakia University https://sites.google.com/a/trakia-uni.bg/artte/

of built up areas, both inside the home and outside. This is because plants are natural filters - taking carbon dioxide from the air and replacing it with much needed oxygen. They also help to filter pollutants from the air. This means that the air that you breathe is much cleaner and healthier.

Plants reduce wind-speed also they prevent dust with wet environments which created with their roots and leaf. By means of this event, plants bring about extinction to harmful microorganisms with onsite sap and juice. Air quality improvement from plants has been shown to reduce coughs by thirty percent and dry throat and irritation by twenty four percent also, the plants clean the office air by absorbing pollutants into their leaves and transmitting the toxin to their roots, where they are turned into food for the plant. With cleaner office air building occupants are less likely to be sick and rooms with plants contain $50 \%$ to $60 \%$ fewer of airborne molds and bacteria than rooms without plants.

Indirectly, living walls reduce air-conditioning requirements and energy consumption of urban buildings through cooling the city. Vegetation on walls can assist in cooling buildings in summer and insulating them in winter. In winter, evergreen species offer a degree of insulation by trapping a layer of air against the facade and reducing convectional heat loss. An insulating effect of up to $30 \%$ has been recorded although such a high percentage is only likely when temperatures fall close to freezing. Energy savings are less significant on well insulated buildings, such as those with brick cavity walls. During the summer, hot walls cause temperatures to rise inside buildings, increasing demand on cooling systems and consuming more energy. A Green Wall surface temperature is reduced when covered with plants, reducing the wall temperature and building cooling load. Green Walls can reduce wall temperature as much as $10^{\circ} \mathrm{C}$ which results in significant air conditioning savings.

As they grow vertically, many pests cannot even get to the plants. This means that you have very little problems with pests attacking your plants so you do not need to use pesticides or insecticides on your plants, saving you using chemicals. As well, air circulates well around the vertical garden and they also get plenty of sunshine, so there is much less risk of the plants suffering from mildew, fungus or disease.

Vertical gardens have demonstrated that restorative effect of natural scenery holds the viewer's attention, diverts their awareness from themselves and from worrisome thoughts and elicits a meditation-like state. They help ease physiological and psychological pressures of city life by providing a spiritual and physical connection to nature. The beauty of a green wall (covering concrete and steel) can rejuvenate our minds and physical fatigue is greatly reduced. The presence of plants in the office not only reduces stress but also helps increase workers' productivity.

Natural habitats are disappearing at an alarming rate, and habitat loss is the number one threat to wildlife today. Green Walls are part of the solution to help restore wildlife habitats. By carefully choosing and planting attractive plant species, a Green Wall will attract birds and butterflies. Green Walls can be designed to provide the ideal conditions for birds, bees and butterflies to survive. It can provide water, food sources, protection, and places to bear and raise offspring.

An urban heat island (UHI) is a metropolitan area which is significantly warmer than its surrounding rural area, especially in late afternoons and nights at winter season. To avoid confusion with global warming, scientists call this phenomenon the "Urban Heat Island Effect. "There are several reasons that may explain the Heat Island Effect, but the main reason is the excessive urban development. Green walls are by far the most popular way to cooling the city. Green Walls in cooling buildings and combating the Heat Island Effect and greatly reduce this effect by absorbing a lot of the heat through the evaporation process. 


\section{ARTTIE $Y$}

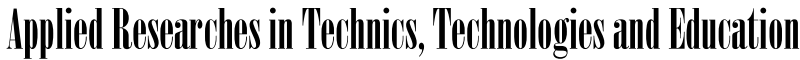

Journal of the Faculty of Technics and Technologies, Trakia University https://sites.google.com/a/trakia-uni.bg/artte/

\section{CONCLUSION}

Green facades, are used for centuries to make residential palaces more beautiful, have been introduced into urban areas in the 20th and 21st centuries. This is the result of new technology. They are currently being designed not only for commercial, but also residential purposes. Vertical gardens are proof that cold, bare walls can give many species of plants the opportunity to grow. City walls can become mini-botanical gardens. Each wall can display the flora typical of a given region. The appropriate selection of plants can give many different species the possibility to grow together in a small area. This can be done by taking into consideration plant growth surfaces, which prevents competition for space.

For building energy efficiency, durability, natural beauty, cost effectiveness and adaptability, green facades offer the design community a substantial asset. The green facade industry continues to evolve and there are a significant number of projects that have thrived for more than a decade, demonstrating a long range return on investment. Installation techniques and construction adaptability will continue to improve, and innovative design applications will be further advanced as designers continue to push the envelope for green facade inclusion. The case for that inclusion can be strengthened by taking the described considerations into account. The completion of this outlined process will help to establish a mainstream acceptance of green facades as a standard building component.

Today, when over half of the world's population lives in cities, we must show that nature can find a place for itself in urbanized environments. Its inclusion would teach city dwellers to be more sensitive towards protecting what is left of the natural environment. It may well be that with the increasing use of green walls in our country, more expensive and effective methods, such as Patrick Blanc's technology, will be applied.

\section{LITERATURE}

[1] Blanc P. The Vertical Garden. From Nature to the City. Revised and Updated, Wydawnictwo W.W. Norton \& Company, London-New York 2012.

[2] Feng Haibo (2008). Lifecycle Based Energy Assessment of Green Roofs and Walls.

[3] Green Walls (2014). <http://www.greenrooftechnology.com/green_walls>. Green Roof Technology.

[4] http://www.greenology.sg/2011/11/benefits-of-vertical-greening-a-discussion.

[5] https://en.wikipedia.org/wiki/Green_wall. 